\title{
Acute tryptase determinations in NSAID-induced anaphylaxis: could we avoid drug challenges?
}

\author{
Esozia Arroabarren ${ }^{*}$, Antonio Rodriguez', Jose Maria Olaguibel', Blanca Garcia', Maria Teresa Aldunate², \\ Maria Alvarez-Puebla1', Sara Garrido', Susana Echechipía', Maria Teresa Lizaso', Marta Anda', Belen Gomez², \\ Ana $\operatorname{Tabar}^{1}$
}

From Food Allergy and Anaphylaxis Meeting 2014

Dublin, Ireland. 9-11 October 2014

\section{Objective}

To seek for possible differences in tryptase values during acute anaphylaxis induced by non-steroid anti-inflammatory drugs (NSAID) related to the suspected mechanism (selective vs non-selective reactions).

\section{Methods}

Retrospective review of patients attending the Emergency Department (2009-2013) for a NSAID induced anaphylaxis and with a tryptase determination. Patients were split into 3 groups according to the allergy workup Results

Selective reactions (S) were defined by positive skin results and/or negative challenges with other NSAID; non-selective (NS) reactions were defined by the existence of symptoms with several NSAID or after positive challenge results. Those cases who did not comply with the previous conditions were non-conclusive (NC). We analysed: demographics, severity of the episode (Chi Square test), and rate of tryptase higher than $11.4 \mathrm{mcg} / \mathrm{l}$ (Chi Square test), median tryptase values and timing of sample obtention (Kruskall-Wallis).

\section{Results}

86 patients were included: $S$ group: 36 patients, NS group: 20 patients, and NC: 30 patients. Median ages were 48,45 and 54 years, respectively. Severity of the episodes: S group: Mild: $22.2 \%$, moderate: $30.6 \%$ and severe: $47.2 \%$; NS group: Mild: $30 \%$, moderate: $35 \%$ and severe: $35 \%$; NC group: Mild: $16.7 \%$, moderate: $26.7 \%$ and severe anaphylaxis: $56.7 \%(\mathrm{p}=0.658)$. The most frequent eliciting drugs were metamizole (19 cases in S group, 7 cases in NS group and 12 in NC group, respectively), acetic derivatives ( 7 cases in $S$ group, 3 cases in NS group and 3 in NC group) and propionic acid derivatives ( 6 cases in S group, 5 cases in NS group and 12 in $\mathrm{NC}$ group). The median of tryptase determinations were: S group: $13.4(2.75-98.6)$, NS: $12.35(3.85-53.6)$ and NC: $13.4 \mathrm{mcg} / \mathrm{l}(2.82-57.1)(\mathrm{p}=0.856)$. Median duration of symptoms: S group: 1.5 (0.33-12), NS: 1.75 (0.5-4); NC: 1.5 hours $(0.5-6 \mathrm{~h})(\mathrm{p}=0.582)$.

\section{Conclusions}

Although there have been reports of differences in tryptase releases during anaphylaxis related to different allergens, we have found no differences among the different patterns of NSAID reactions that may help us to avoid future challenges for diagnostic confirmation.

\section{Authors' details}

${ }^{1}$ Complejo Hospitalario de Navarra, Pamplona, Spain. ${ }^{2}$ Hospital Reina Sofia de Tudela, Pamplona, Spain.

Published: 30 March 2015

doi:10.1186/2045-7022-5-S3-P144

Cite this article as: Arroabarren et al:: Acute tryptase determinations in NSAID-induced anaphylaxis: could we avoid drug challenges? Clinical and Translational Allergy 2015 5(Suppl 3):P144.

${ }^{1}$ Complejo Hospitalario de Navarra, Pamplona, Spain

Full list of author information is available at the end of the article 